\title{
Rapp-Hodgkin Syndrome with palmoplantar keratoderma
}

\author{
wissal abdelli ${ }^{1}$, Asmahene Souissi ${ }^{1}$, Wiem Sassi $^{1}$, Fatima Alaoui $^{1}$, and Mourad Mokni ${ }^{1}$ \\ ${ }^{1}$ Rabta Hospital
}

January 13, 2022

\begin{abstract}
Rapp-Hodgkin syndrome is a rare condition that is characterized by ectodermal dysplasia and palatal abnormalities. We describe a 15-year-old male who has Rapp-Hodgkin syndrome that is associated with a palmoplantar keratoderma.
\end{abstract}

\section{INTRODUCTION}

Ectodermal dysplasias (ED) are a heterogeneous group of disorders resulting from abnormalities of structures derived from embryonic ectoderm. Rapp-Hodgkin syndrome (RHS) was first described over 30 years ago in an affected mother, son, and daughter with a combination of ED, cleft lip and cleft palate (1). Other features include narrow nose, thin coarse hairs, hypodontia with hypoplastic enamel and malformed teeth, hyponychia, anonychia, narrow or dystrophic nails, lacrimal duct abnormalities, ear and ear canal abnormalities (2). Here, we describe a 15-year-old male who has RHS associated with palmoplantar keratoderma.

\section{Case report}

A 15-year-old male was born to unaffected, second degree consanguineous parents. He was referred to our outpatient departement for palmoplantar keratoderma evolving over the last few months. During the childhood, his hair was light colored and coarse. He began to lose it since his teenage years. He also complains of heat intolerance and a reduced ability to sweat. The patient had dental prosthesis due to caries and dental malformation. A cleft palate was repaired in childhood. A dacryocystorhinostomy and a nephrectomy were practiced too. There was no history of similar cases in the family.

On physical examination, the patient measured $161 \mathrm{~cm}$ in height. We noticed diffuse bilateral palmoplantar keratoderma with palmoplantar pits. Bilateral ulcerations covered by thick and honey-colored crusts with underlying erythema were observed on the palms and mainly on the carpus (Fig.1) .

He also demonstrated a striking facial morphology consisting of a frontal bossing, a short philtrum, a thin upper lip, a mildly dysmorphic auricles and prognathism (Fig.2). Skin was dry with discrete scaling. An occasional light-colored, wiry hair was found on an otherwise alopecic scalp. His eyebrows and eyelashes were scarce.

All his nails were dysplastic. They were narrow and small with pterygium and longitudianl ridging (Fig.3 ) .

In view of hypohidrotic ectodermal dysplasia associated with orofacial clefting, genitourinary abnormalities, hypodontia, hair involvement and lacrimal duct anomaly, the diagnosis of RHS was made.

\section{Discussion}

RHS is considered one of the groups of disorders categorized by findings of ectodermal dysplasia and clefting. It's generally inherited in an autosomally dominant fashion but sporadic mutations do occur as in our case 
(3). There is increasing evidence that symptoms of RHS are caused by defects in the transcription factor p63 (4).

The palate, hair, eyes and nails are the four areas particularly affected (1). Cleft palate is the cardinal feature of this syndrome $(1,5)$. Our patient's cleft palate was repaired in childhood.

Patients commonly had blond coarse, wiry, woolly, fine, dry, slowly growing, short hair or hypotrichosis. They showed stiff, uncombable, brittle and kinky hair with a "steelwool appearance", breaking by combing, furthermore lusterless, soft, thick or thin hair (4). Hair loss at puberty is also a reported characteristic (6). This feature was observed in our patient and he is now alopecic with a few fragile, sparse hairs. The craniofacial features, including high forehead, narrow nose, thin upper lip and hypoplastic maxilla, with a high arched palate seem to be typical for this ED syndrome (4). Hypodontia and malformation are frequently observed in RHS leading to esthetic and psychological problems (4). There are good possibilities using removable prostheses to help these children. Patients commonly had onychodysplasia and hypoplastic nails (5), as reported in our patient.

Hidrotic ED, the most common form of ED, occurs in $\sim 1$ in 5000-10 000 births. Our patient had an hidrotic ED with bilateral palmoplantar keratoderma and occasional ulcerations on the palms. Palmoplantar keratoderma is a common but not universal feature of hidrotic ED which increases in severity with age (6). It's most often linked to heterozygous mutations in GJB6, gap junction beta-6 protein (Connexin 30) (7). However, a literature search revealed only five reports of palmoplantar keratoderma in hypohidrotic ED (8-10). It is considered an uncommon manifestation of Hidrotic ED. Ulcerations on the palms as in our patient are not common in RHS. O'Donnell BP et al reported the case of a 24-year-old woman with RHS, she had occasional bilateral ulceration on the palms too (11).

\section{Figures legend}

Fig.1 : palmar keratoderma

Fig.2 : facial features of Rapp Hodgkin Syndrome

Fig.3 : dysplastic nails

\section{Author Contributions}

1. ABDELLI Wissal : Writing the article

2. SOUISSI Asmahen, ALAOUI Fatima, SASSI Wiem: Been involved in drafting the manuscript and revising it critically

3. Mokni Mourad : Given final approval of the version to be published

\section{Data availability statement}

The data used to support the findings of this study are included within the article.

\section{Ethical statement}

I testify on behalf all co-authors that our article submitted to the clinical case reports : Rapp-Hodgkin Syndrome with palmoplantar keratoderma.

-this material has not been published in whole or in part elsewhere.

-the manuscript is not currently beeing considered for publication in other journal

-all authors have been personally and actively involved in substantive word leading to the manuscript, and will hold themselves jointly and invidually responsible for its content.

\section{References}

1. Tosun G, Elbay U. Rapp-Hodgkin Syndrome: Clinical and Dental Findings. J Clin Pediatr Dent. 3 nov 2009;34(1):71-5. 
2. Chatterjee M, Neema S, Mukherjee S. Rapp Hodgkin Syndrome. Indian Dermatol Online J. 2017;8(3):2156 .

3. Kim G, Shin H. Rapp-Hodgkin syndrome. Dermatol Online J. 2004;10(3):23.

4. Knaudt B, Volz T, Krug M, Burgdorf W, Röcken M, Berneburg M. Skin symptoms in four ectodermal dysplasia syndromes including two case reports of Rapp-Hodgkin-Syndrome. Eur J Dermatol. 2012;22(5):60513.

5. Breslau-Siderius EJ, Lavrijsen APM, Otten FWA, Schroeff JG van der, Swart JGN. The Rapp-Hodgkin syndrome. Am J Med Genet. 1991;38(1):107-10.

6. Park SW, Yong SL, Martinka M, Shapiro J. Rapp-Hodgkin syndrome: A review of the aspects of hair and hair color. J Am Acad Dermatol. 2005;53(4):729-35.

7. Wright JT, Fete M, Schneider H, Zinser M, Koster MI, Clarke AJ, et al. Ectodermal dysplasias: Classification and organization by phenotype, genotype and molecular pathway. Am J Med Genet A. 2019;179(3):4427 .

8. Kothiwala SK, Prajapat M, Kuldeep C. Christ-Siemens-Touraine syndrome with palmoplantar keratoderma: A rare association. Indian Dermatol Online J. 2016;7(5):393-5.

9. Pozo-Molina G, Reyes-Reali J, Mendoza-Ramos MI, Villalobos-Molina R, Garrido-Guerrero E, MendezCruz AR. Novel missense mutation in the EDA1 gene identified in a family with hypohidrotic ectodermal dysplasia. Int J Dermatol. 2015;54(7):790-4.

10. M DB, L F, S M, I K. An unusual manifestation of X-linked hypohidrotic ectodermal dysplasia with palmoplantar keratoderma. Clin Exp Dermatol. 2019;45(3):352-3.

11. O’Donnell BP, James WD. Rapp-Hodgkin ectodermal dysplasia. J Am Acad Dermatol. 1992;27(2, Part 2):323-6.

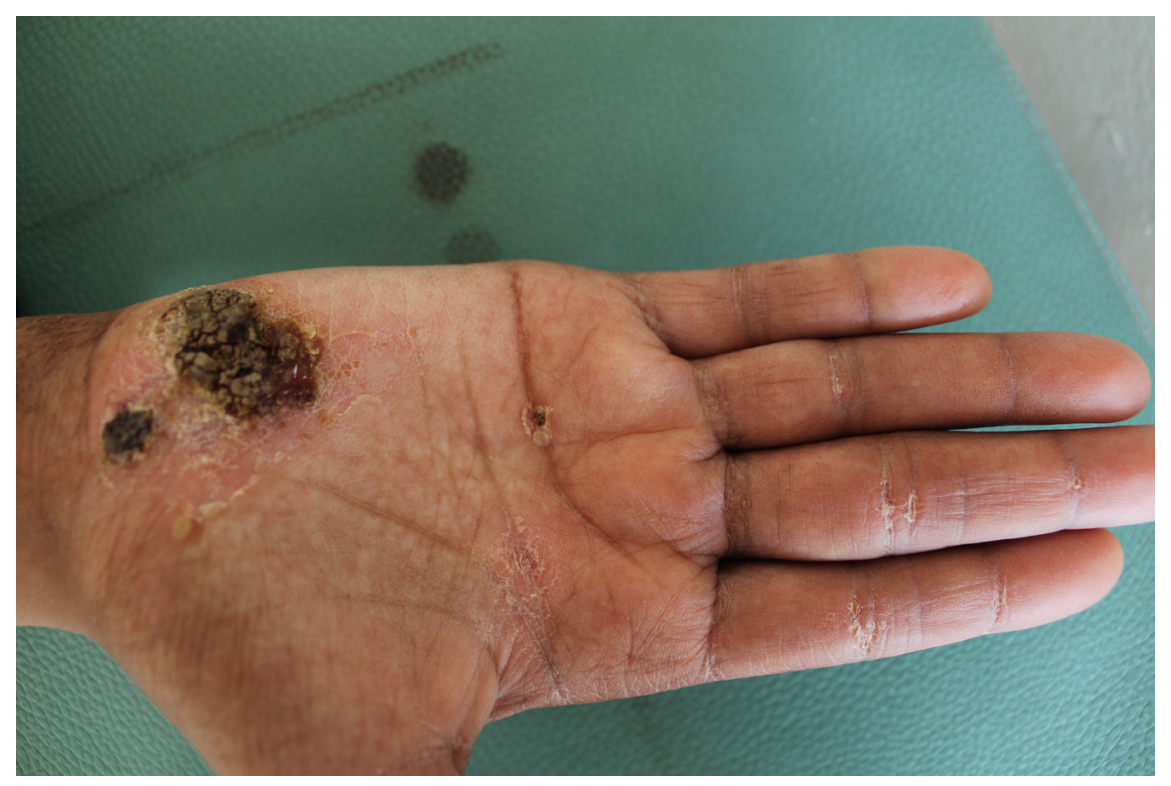




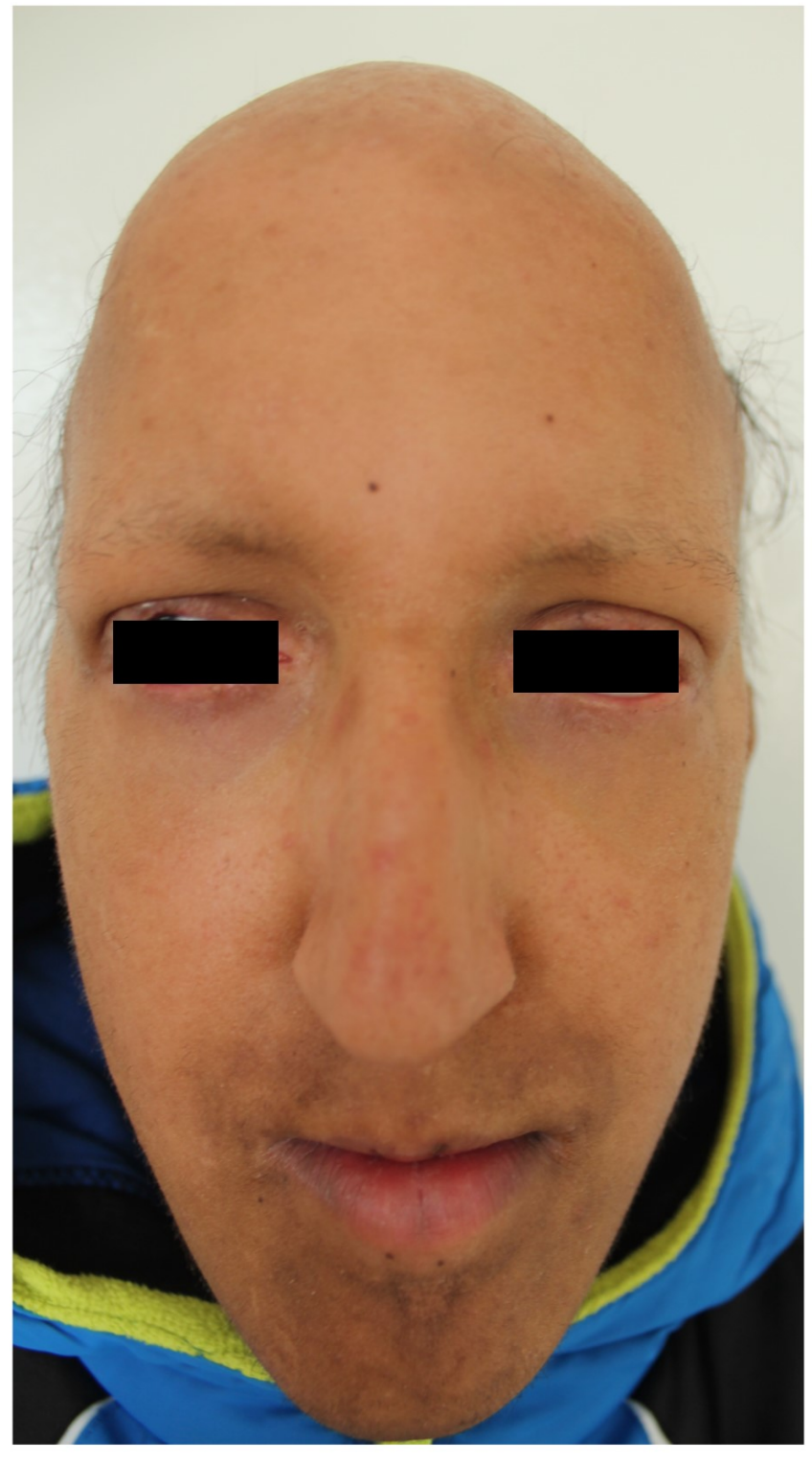




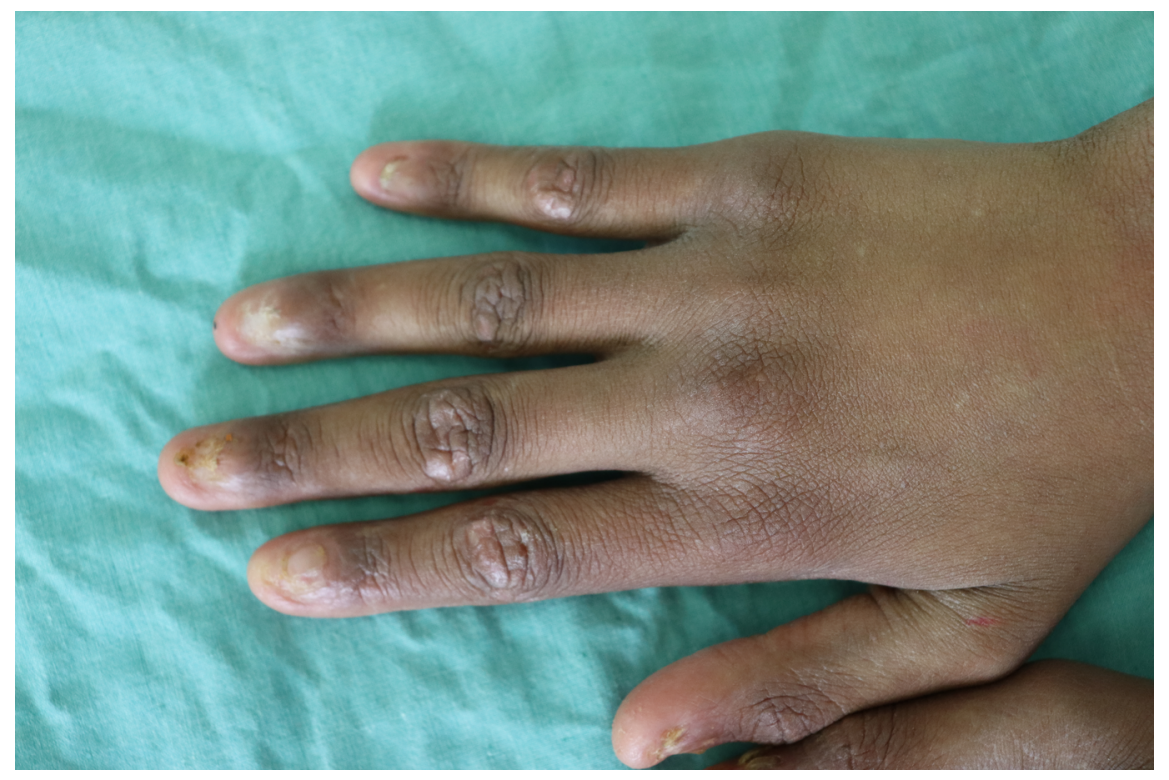

